\title{
Trafik Kazalarına Etki Eden Faktörler Arasındaki İlişkilerin TBA Biplot Analiz Yöntemi İle Değerlendirilmesi
}

\author{
Emre TERCAN ${ }^{1}$, Erkan BEŞDOK ${ }^{2}$
}

ÖZET: Trafik kazaları Türkiye'de en önemli sorunlar arasında yer almaktadır. Trafik kazaları çok sayıda can ve mal kaybına neden olmakta ve toplum üstünde olumsuz sosyal ve psikolojik etkiler yaratmaktadır. Ölümlü veya yaralanmalı kazalara neden olabilecek durumların belirlenmesi, koruyucu, uyarıcı ve önleyici tedbirlerin alınması için oldukça önemlidir. Bu sebeple trafik kazalarına neden olan parametreler arasındaki ilişkilerin değerlendirilmesi gerekmektedir. Değişken sayısının ikiden fazla olması halinde, çok değişkenli verinin görsel şekilde açıklanması oldukça karmaşıktır. Çok değişkenli veri setinin geometrik olarak daha az boyutta yorumlanmasında biplot analiz yöntemi oldukça kullanışlıdır. Bu makalede, yedi farklı bölünmüş karayolundaki trafik kazaları veri seti Temel Bileşenler Analizi (TBA) biplot yöntemi ile de ğerlendirilmiştir. Bu çalışmanın amacı, ölümle ve yaralanmayla sonuçlanan trafik kazalarına neden olan parametreler arasındaki ilişkilerin araştırılmasıdır. Elde edilen sonuçlar gün (gece), gün (gündüz), çok araçlı, tek araçlı, kaza tipi (yoldan çıkma), kavşak yok ve kavşak var parametrelerinin ölümlü ve yaralanmalı kazalarda en önemli parametreler olduğunu göstermektedir. Trafik kazalarına etki eden parametreler arasındaki ilişkilerin biplot yöntemi ile değerlendirilmesi, trafik kazalarını azaltıcı ve önleyici tedbirlerin geliştirilmesine katkı sağlayacak ve gelecekte yapılacak çalışmalara önemli bir zemin oluşturacaktır.

Anahtar Kelimeler: Trafik kazası, karayolu, biplot analizi, TBA biplot

\section{Evaluation of Relations Between Factors Affecting Traffic Accidents by PCA Biplot Analysis Method}

\begin{abstract}
Traffic accidents are among the most important problems in Turkey. Traffic accidents cause a lot of loss of life and property and cause negative social and psychological effects on the society. Determination of the conditions that could result in a fatal or injured accident is very important for taking preventive, warning and preventive measures. For this reason, it is necessary to evaluate the relationships between the parameters that cause traffic accidents. If the number of variables is more than twice, it is very complicated to visualize the multivariate data visually. The Biplot analysis method is very useful for interpreting a multivariate dataset with less geometric dimensions. In this article, the traffic accidents data set on seven different divided roadways was evaluated by Principal Components Analysis (PCA) biplot analysis method. The aim of this study is to investigate the relationships between parameters that cause traffic accidents resulting in fatal and injury. The results show that day (night), day (daylight), multi-vehicle, single vehicle, accident type (run-off-road), no intersection and intersection parameters are the most important parameters in fatal and injured accidents. The evaluation of the relationships between parameters affecting traffic accidents by biplot method will contribute to the development of preventive measures to reduce traffic accidents and will constitute an important ground for future studies.
\end{abstract}

Keywords: Traffic accident, roadway, biplot analysis, PCA biplot

\footnotetext{
Emre TERCAN (0000-0001-6309-1083), Karayolları Genel Müdürlüğü, 13.Bölge Müdürlüğü Etüt Proje ve Çevre Başmühendisliği, Antalya, Türkiye

Erkan BEŞDOK (0000-0001-9309-375X), Erciyes Üniversitesi, Mühendislik Fakültesi Harita Mühendisliği Bölümü, Kayseri, Türkiye Sorumlu yazar/Corresponding Author: Emre TERCAN, emre_tercan@hotmail.com
} 


\section{GíRIŞ}

Dünya genelinde trafik kazalarında yılda takriben 1.2 milyondan fazla kişi ölmekte, takriben 50 milyon kişi yaralanma veya sakat kalma vakalarına maruz kalmaktadır. Trafik kazaları dünya genelinde ölümlerin on temel sebebi arasında yer alıp dokuzuncu ölüm sebebi olarak görülmektedir (WHO, 2016). Trafik güvenliğinin sağlanmaması ve gerekli tedbirlerin alınmaması durumunda, 2020 yılına kadar dünyada trafik kazalarında ölen ve yaralanan kişi sayısının \%65 artacağ 1,2030 yılı itibarıla trafik kazalarında yaralanma sonrası meydana gelebilecek ölüm vakalarının ölüme sebep olabilecek tüm faktörler açısından beşinci sıraya geleceği öngörülmektedir. Halen dünyanın pek çok ülkesinde trafik kazaları her yıl yaralanma ve kalıcı bedensel işlev kaybı vakaları nedeniyle felaket düzeyinde sosyo-ekonomik kayba neden olmaktadır (WHO, 2016; Tercan, 2017).

Türkiye'de nüfus ve trafiğe katılan motorlu araç sayısı hızla artmaktadır. Ulaştırma türleri arasında karayolu ulaşımının diğer ulaştırma türlerine göre daha fazla tercih edilmesi karayolu ağı üzerindeki trafik yoğunluğunu artırmıştır. Karayolu bakım, işletme ve iyileştirme çalışmalarındaki olumsuzluklar, kavşak tasarım hataları ve uygun olmayan kavşak tipinin seçilmesi, demiryolu ağının ve akıllı ulaştırma sistemlerinin yeterince yaygınlaşmaması gibi kamusal kararlar yetersiz kalmaktadır. Yük ve yolcu talebinin artış eğiliminde olması, çevresel ve meteorolojik faktörlerden kaynaklanan sorunlar ve yol kullanıcılarının olumsuz eylemleri trafik kazalarını ayrıca arttırmaktadır.

Trafik kazaları, dünya genelinde ciddi bir sorun olduğu gibi Türkiye'de de en önemli sorunlar arasında yer almakta ve her yıl kazalara bağlı olarak çok sayıda insan ölmekte, yaralanmakta ve sakat kalmaktadır. Türkiye'de 2016 yılı trafik kazası verilerine göre gün başına ortalama 3240 adet trafik kazası meydana gelmiş, trafik kazalarına bağlı olarak 20 kişi hayatını kaybetmiş ve 832 kişi yaralanmıştır. Türkiye' de son beş yılda gerçekleşen 851509 adet ölümlü-yaralanmalı trafik kazasında toplam 25789 kişi ölmüş, 1436200 kişi yaralanmış veya sakat kalmıştır (KGM, 2016). Bu istatistiksel sonuçlar, trafik kazalarının Türkiye için çok önemli bir sosyo-ekonomik problem olduğunu göstermektedir.
Karayollarında, trafik kazalarına neden olan en önemli parametreler insan davranışları (sürücü, yolcu ve yaya davranışları), araç özellikleri (araçların yapısı, yaşı, türü gibi), yol, çevre ve meteorolojik etkenlerdir.

Trafik kazaları can ve mal kayıplarına, toplum üstünde olumsuz sosyal ve psikolojik etkilere sebep olduğu için ciddi anlamda araştırılması ve köklü çözümler üretilmesi gereken bir problem olarak görülmektedir. $\mathrm{Bu}$ nedenle trafik kazalarını azaltmak ve önleyici tedbirler alabilmek için trafik kazalarına neden olan parametreler arasındaki ilişkilerin değerlendirilmesi gerekmektedir.

Biplot yöntemi, çok değişkenli bir veri kümesinin ayrıntılı olarak özetlenmesine yardımcı olmaktadır. Biplotlar değişken sayısı kadar eksene sahiptir. Biplot grafiğinde tüm değişkenler üzerinde herhangi bir gözlemin dik izdüşümü, ilgili gözlemin tüm değişkenler üzerinde aldığı değerleri sağlamaktadır. Bu çalışmada kullanılan asimetrik biplot'un en basit ve en yaygın şekli olan Temel Bileşenler Analizi (TBA) biplot gözlemler ve değişkenler arasındaki ilişkilerin tanımlanması için kullanılan çok değişkenli istatistiksel bir yöntemdir. TBA biplot, veri yapısının yorumlanmasına yardımcı olmakta ve önemli değişkenler ya da gözlemlerin belirlenmesi için olanak sağlamaktadır (Alkan, 2011; Tercan, 2017).

Biplot analiz yöntemleri ile jeokimya (Sierra et al., 2017; Librero et al., 2017), gida analizi (Alkan ve Atakan, 2011; Martin et al., 2017), tarımsal ürün verim değerlendirme (Kadariya et al., 2008; Kendal ve ark., 2014; Tekdal ve ark., 2014; Sayar ve Han, 2015; Zhang et al., 2016; Kabak ve Akçura, 2017), saplantı zorlantı bozukluğu (Kim et al., 2016), bilim insanlarının performanslarının değerlendirilmesi (Faes et al., 2015), kurumsal sosyal sorumluluk değerlendirme (Esteban et al., 2017) gibi farklı disiplinlerde çalışmalar yürütülmektedir.

Literatürde trafik kazalarının modellenmesi amaciyla regresyon analizi (Al Ghamdi, 2002; Yau, 2004; Tortum et al., 2012; Çodur ve ark., 2013), yapay sinir ağları (Kunt et al., 2012; Alikhani et al., 2013), sınıflandırma ve regresyon ağaçları (Kashani and Mohaymany, 2011; Chang and Chien, 2013), bayes ağları (Mujalli and De Ona, 2011; De Ona et al, 2013) gibi yöntemler kullanılarak çalışmalar yürütülmektedir. 
Al-Ghamdi (2002), Suudi Arabistan'ın başkenti Riyad'da trafik kazası şiddeti üzerinde, farklı değişkenlerin etkisini incelemek için trafik kazasına ait verilere lojistik regresyon uygulamıştır. Kaza yaralanma şiddetine etki eden önemli parametreler kaza sebebi ve kaza konumu olarak belirlenmiştir. Yau (2004), Hong Kong'da belirli bir bölgedeki motorlu araç kazalarında, yaralanma şiddeti üzerinde konum, çevre, güvenlik, araç, insan ve mahalli faktörlerin etkisini incelemek için aşamalı lojistik regresyon modelini kullanmıştır. Özel araçlarda, bölge, sürücü cinsiyeti, araç yaşı, kaza zamanı ve 1şık durumu; tehlikeli madde taşıyan araçlarda, emniyet kemeri kullanımı ve kazanın hafta içi meydana gelmesi; motorsiklet kazaları için, araç yaşı, kazanın hafta içi meydana gelmesi ve kaza zamanı trafik kazası yaralanma şiddetine etki eden önemli faktörler olarak belirlenmiştir. Çodur ve ark., (2013), Erzurum Kuzey Çevre Yolu'nda 2005-2010 yılları arasındaki trafik kaza verilerini kullanarak trafik kazalarına etki eden faktörler arasındaki ilişkilerin değerlendirilmesi için Genelleştirilmiş Lineer Regresyon yöntemini kullanmışlardır. Mevcut bölünmüş yollarda kazaya karışan ağır taşıtların yüzdesi, yaz mevsiminde olan kazaların yüzdesi ve yatay kurp sayısı arttığında kaza sayılarının azaldığını; buna karşın düşey kurp sayısının, yol kesim kilometresinin ve yıllık ortalama günlük trafiğin (YOGT) artması ile kaza sayılarının arttığ belirlemişlerdir.
Literatürde trafik kaza parametreleri arasındaki ilişkilerin biplot yöntemi ile değerlendirilmesine ilişkin bir çalışma bulunmamaktadır. Bu makalede, ilgili bölünmüş devlet yollarında meydana gelen trafik kazalarına ait resmi raporlarından derlenen 25 parametreden oluşan trafik kaza veri seti biplot yöntemi ile analiz edilerek ölümle ve yaralanmayla sonuçlanan trafik kazalarına neden olan parametreler arasındaki ilişkilerin araştırılması amaçlanmıştır. Bu çalışmada ele alınan trafik kazalarına etki eden parametreler arasındaki ilişkilerin biplot yöntemi ile değerlendirilmesi, trafik kazalarını azaltıcı ve önleyici tedbirlerin geliştirilmesine katkı sağlayacak ve gelecekte yapılacak çalışmalara önemli bir zemin oluşturacaktır.

\section{MATERYAL VE YÖNTEM}

\section{Çalışma Alanı ve Veri Seti}

Türkiye'de trafik kazalarının sıklıkla meydana geldiği ve bu kazalar sonucunda önemli ölçüde can ve mal kayıplarının oluştuğu,Karayolları Genel Müdürlüğü sorumluluğunda bulunan 7 adet aks içerisinden 30 farklı kontrol kesim noktası (KKNO) çalışma alanı olarak seçilmiştir (Şekil 1 ve Çizelge 1) (Tercan, 2017). Çalışma alanı yolların tamamı bölünmüş devlet yolu statüsündedir ve üst yapısı bitümlü sıcak karışımdır.

Çizelge 1. Çalışma Yapılan Bölünmüş Yol Güzergâhları (Tercan, 2017)

\begin{tabular}{|c|c|c|c|}
\hline No & Aks Adı & Kontrol Kesim No & Uzunluk (Km) \\
\hline 1 & Sivrihisar-Polatlı-Ankara Yolu & $200-10 / 11 / 12$ & 104 \\
\hline 2 & Aydın-Denizli-Çardak Yolu & $320-01 / 02 / 03 / 04$ & 178 \\
\hline 3 & Balıkesir-Akhisar-Manisa Yolu & $568-08 / 09$ & 96 \\
\hline 4 & Erzincan-Erzurum-Ağrı-Doğubeyazıt-Gürbulak Yolu & $100-26 / 27 / 28 / 29 / 30 / 31 / 32 / 33$ & 194 \\
\hline 5 & Ankara-Şereflikoçhisar-Aksaray Yolu & $750-08 / 09 / 10 / 11$ & 217 \\
\hline 6 & Yozgat-Yıldızeli-Sivas-Zara-Refahiye Yolu & $200-20 / 21 / 22 / 23$ & 214 \\
\hline 7 & Kınalı (Ayrım)-Tekirdağ-İpsala Yolu & $110-01 / 02 / 03 / 04 / 05$ & \multirow{2}{*}{} \\
\hline
\end{tabular}

Türkiye'de trafik kazalarını etkileyen parametreler arasındaki ilişkileri yorumlamak için veri seti, ülkenin farklı bölgelerinde yer alan 30 farklı bölünmüş yola ait 2012-2013 yıllarında gerçekleşen trafik kazalarına ait resmi raporlardan derlenmiştir (Tercan, 2017). 


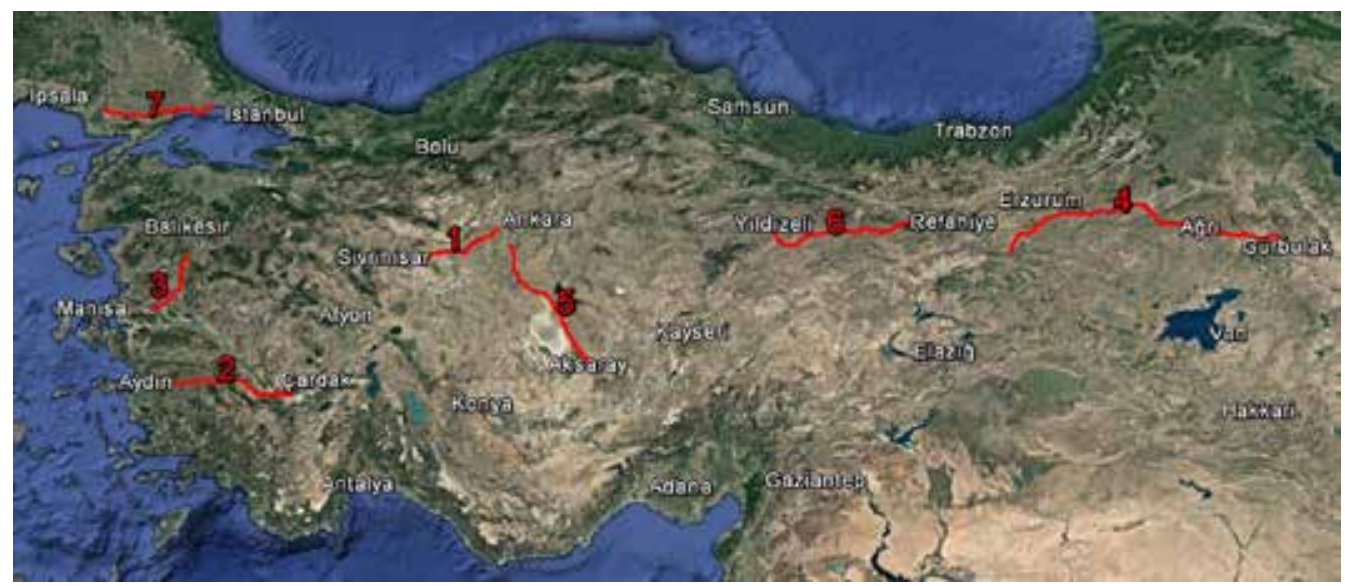

Şekil 1. Çalışma Alanı Olarak Belirlenen Devlet Yolları (Tercan, 2017)

Bu çalışmada kullanılan trafik veri seti, çalışma alanı olarak seçilen devlet yollarında 2012-2013 y1llarında meydana gelen 8078 trafik kazasina ait resmi raporlardan derlenen 25 farklı parametre içermektedir. Trafik kazalarına rölatif olarak en çok etki eden söz konusu parametreler Çizelge 2'de verilmiştir (Tercan, 2017).

Çizelge 2. Trafik Kazalarına Etki Eden Veri seti parametreleri (Tercan, 2017)

\begin{tabular}{|c|c|c|c|}
\hline \multirow{2}{*}{ No } & \multirow{2}{*}{ Parametre } & \multicolumn{2}{|c|}{ Kodlama } \\
\hline & & 0 (Hayır) & 0 (Evet) \\
\hline 1 & Yerleşim yeri içi mi? & 0 & 1 \\
\hline 2 & Yerleşim yeri dışı mı? & 0 & 1 \\
\hline 3 & Araç sayısı =1 mi? & 0 & 1 \\
\hline 4 & Araç sayısı>1 mü? & 0 & 1 \\
\hline 5 & Hava durumu açık mı? & 0 & 1 \\
\hline 6 & Hava durumu yağmurlu mu? & 0 & 1 \\
\hline 7 & Hava durumu sisli veya karlı mı? & 0 & 1 \\
\hline 8 & Gün durumu gündüz mü? & 0 & 1 \\
\hline 9 & Gün durumu gece veya alacakaranlık mı? & 0 & 1 \\
\hline 10 & Yol üst kaplaması kuru mu? & 0 & 1 \\
\hline 11 & Yol üst kaplaması 1slak mı? & 0 & 1 \\
\hline 12 & Yol üst kaplaması buzlu veya karlı mı? & 0 & 1 \\
\hline 13 & Yatay geometride aliyman var mı? & 0 & 1 \\
\hline 14 & Yatay geometride kurp var mı? & 0 & 1 \\
\hline 15 & Yol düşeyde eğimli mi? & 0 & 1 \\
\hline 16 & Yol düşeyde eğimsiz mi? & 0 & 1 \\
\hline 17 & Yolda kavşak var mı? & 0 & 1 \\
\hline 18 & Yolda kavşak yok mu? & 0 & 1 \\
\hline 19 & Kaza tipi arkadan çarpma mı? & 0 & 1 \\
\hline 20 & Kaza tipi devrilme mi? & 0 & 1 \\
\hline 21 & Kaza tipi yoldan çıkma mı? & 0 & 1 \\
\hline 22 & Kaza tipi yandan çarpma mı? & 0 & 1 \\
\hline 23 & Kaza tipi duran araca, yayaya, hayvana, sabit cisme çarpma mı? & 0 & 1 \\
\hline 24 & Ölüm var mı? & 0 & 1 \\
\hline 25 & Yaralanma var mı? & 0 & 1 \\
\hline
\end{tabular}




\section{Biplot Analiz Yöntemi ve TBA (Temel Bileșenler Analizi) Biplot}

İki değişken üzerinde $n$ gözlemden oluşan bir veri kümesi, iki boyutlu bir nokta saçılım grafiğinde basit bir şekilde yorumlanabilir. Değişken sayısının ikiden fazla olması halinde, çok değişkenli verinin görsel şekilde açıklanması oldukça karmaşıktır. Çok değişkenli veri setinin geometrik olarak daha az boyutta yorumlanması biplot olarak tanımlanan grafiksel bir yöntem ile gerçekleştirilir. Boyut indirgemesi çoğunlukla veri kaybına yol açar. Biplotların amacı, verideki bu kaybın minimizasyonu için bazı kriterleri optimize etmektir. Optimize edilmiş kriterlere bağlı olarak, biplotların çeşitli tipleri bulunabilir. Biplot yöntemi, çok değişkenli bir veri kümesinin ayrıntılı olarak özetlenmesine yardımcı olur. Biplotlar, değişken sayısı kadar eksene sahiptir. Biplot grafiğinde tüm değişkenler üzerinde herhangi bir gözlemin dik izdüşümü, ilgili gözlemin tüm değişkenler üzerinde aldı $\breve{1}$ değerleri sağlar. Gözlemlerin değişkenler üzerinde aldığı değerlere kesin olarak ulaşılamamaktadır (Alkan, 2011; Tercan, 2017). Gözlemleri ve değişkenleri eş zamanlı olarak gösterebilen biplot yöntemi bir veri matrisinin görsel analizi için kullanılabilir (Alkan ve ark., 2015).

Biplot yöntemi, Gabriel (Gabriel, 1971; Gabriel, 1978) tarafından bir veri matrisinin önemli özelliklerini göstermek için önerilmiştir. Gabriel'in biplot tekniği, Gower ve Hand'in (Gower and Hand, 1996) fikirleriyle yeni bir bakış açısı kazanmıştır. Daha sonra farklı biplot yöntemleri geliştirilmiştir (Gower, 2004; Gardner and Le Roux, 2005; Gower et al., 2011; Alkan, 2011).

Asimetrik biplot'un en basit ve en yaygın şekli olan Temel Bileşenler Analizi (TBA) biplot, $X$ veri kümesinin değişkenlerini ve gözlemlerini aynı uzayda incelediğinden asimetriktir. Ayrıca asimetrik form, veri matrisinin kovaryans veya korelasyon yapısını ifade eder. TBA biplot, TBA sonuçlarını görsel olarak göstermek için kullanılır. TBA biplot gözlemler ve değişkenler arasındaki ilişkilerin tanımlanması için kullanılan çok değişkenli istatistiksel bir yöntemdir. TBA biplot, veri yapısının yorumlanmasına yardımcı olur ve önemli değişkenler ya da gözlemlerin belirlenmesi için olanak sağlamaktadır (Alkan, 2011; Tercan, 2017).
TBA biplotta, yalnızca tek bir değişken kümesi $X: N X P$, ana bileşenler kümesine $T=X_{0} V_{[A]}$ ayrıştırılmaktadır. Burada; $\quad V_{[A]}, \quad X_{0}=U D V^{T}$ 'nin doğru tekil vektörlerinin ilk A sütunlarını içermektedir. Ayrıca $X^{\prime}$ 'in en iyi A boyutlu yaklaşımı $X_{0}=X_{0} V V^{T} \cong X_{0} V_{[A]} V_{[A]}^{T}=T V_{A}^{T} \quad$ ile verilebilir (Eckart and Young, 1936; Oyedele and Lubbe, 2015). TBA biplotta, örnekler $\mathrm{T}$ siraları ile tanımlanan sıra işaretleyiciler ile temsil edilmektedir. Biplot eksenlerinin yönleri V[A] matrisinin satırları tarafından verilmektedir (Oyedele and Lubbe, 2015).

Gower ve Hand (Gower and Hand, 1996) sirasiyla A boyutlu biplot uzayındaki $P$ boyutlu bir örneğin konumunu bularak ve A boyutlu biplot uzayındaki herhangi bir nokta için $\mathrm{P}$ orijinal değişkenlerinin değerlerini çıkararak enterpolasyon ve tahmin işlemlerini tanımlamışlardır. Bu yazarlar, bir örnek verildiğinde biplot uzayına $t^{T}=(x-\bar{x})^{T} V_{[A]}$ eşitliği ile enterpole edildiğini göstermektedir. Burada; $\bar{x}$, x'in sütun ortalamalarıdır. k. değişken için öngörülen biplot eksenini izlemek için $\mu_{0}$ değerleri $\left(\mu_{0} / e_{k}^{T} V_{[A]} V_{[A]}^{T} e_{k}\right) V_{[A}^{T} e_{k}$ ifadesinde yerine konulmaktadır. Burada $e_{k}$ k. konum için bir tanesi dışında sıfırlar içeren birim vektördür. $\mu_{0}$ değerleri merkezlenmiş gözlemlere bağlıdır ve kalibrasyon işaretleri duyarlı ölçek işareti değerlerine uydurulur (Oyedele and Lubbe, 2015). Bu yönteme ait teorik altyapıya ilişkin detaylı tanımlamalar (Gower and Hand, 1996; Alkan, 2011; Gower et al., 2011)'de bulunabilir.

Bu çalışmada, yedi farklı bölünmüş karayolundaki trafik kazaları veri seti TBA biplot analiz yöntemi ile MATLAB yazılımı kullanılarak değerlendirilmiştir.

\section{BULGULAR VE TARTIŞMA}

Ölümlü kazalara ait gözlemlerin diğer gözlemlerle olan pearson korelasyon değerlerinin ortalamaları hesaplanmıştır. Elde edilen ortalama korelasyon değerleri için $N(\mu, \sigma)=N(0.3877,0.1394)$ olarak hesaplanmıştır. Ortalama $r$ değerleri, üç histogram bandında incelendiğinde ölçülerin \%71.82'si [.3915 $\max (\mathrm{r})]$ aralığında yığılmıştır. Yaralanmalı kazalara ait 
gözlemlerin diğer gözlemlerle olan pearson korelasyon değerlerinin ortalamaları ayrıca hesaplanmıştır. Elde edilen ortalama korelasyon değerleri için $N(\mu, \sigma)=N(0.3290,0.1494)$ olarak hesaplanmıştır. Ortalama $r$ değerleri, üç histogram bandında incelendiğinde ölçülerin \%85.11'i [.3307 $\max (\mathrm{r})]$ aralı̆̆ında yı̆̆glmıştır. Elde edilen bu basit istatistiksel sonuçlar, trafik kazalarını incelemek için seçilen parametrelerin, ölümlü ve yaralanmalı trafik kazalarını incelemek için kullanılabileceklerini göstermektedir (Tercan, 2017).

Şekil 2 ve Şekil 3'de verilen biplot analiz grafikleri, ölümlü ve yaralanmalı trafik kazalarına etki eden parametreler arasındaki ilişkilerin yorumlanmasına katkı sağlamaktadır. Biplot analizi, değişkenlerin seçilen sayıdaki ana bileşenleri üzerindeki katkılarını inceler. Gerçekleştirilen biplot analizine göre ölümlü kazalar için 1 . ve 2 . ana bileşenler için en etkili parametrelerin sırasıyla gün (gece), gün (gündüz), çok araçlı, tek araçlı, tipi (yayaya ve sabit cisme çarpma), tipi (yoldan çıkma), tipi (yandan çarpma), kavşak var, kavşak yok olduğu belirlenmiştir (Şekil 2). Yerleşim dış1, kavşak yok ve tipi (yoldan çıkma) parametreleri pozitif korelasyona sahiptir. Yerleşim içi, kavşak var, tipi (yandan çarpma) parametreleri pozitif korelasyona sahiptir (Şekil 2). Bu durum trafik kazası verilerinin anlamlı olduğunu da göstermektedir (Tercan, 2017).

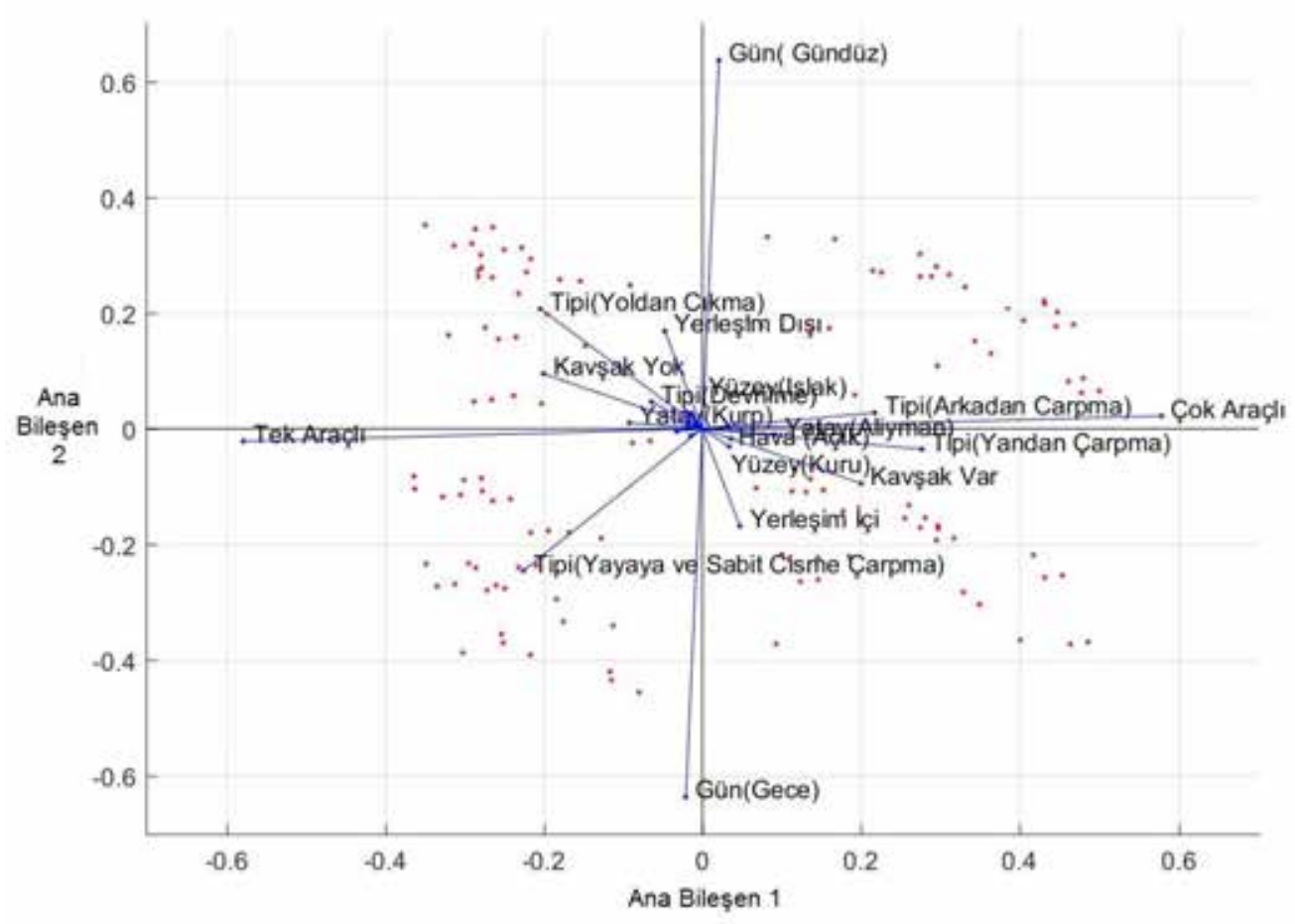

Şekil 2. Ölümlü trafik kazası verilerine ait biplot analizi (Tercan, 2017)

Gerçekleştirilen biplot analizine göre yaralanmalı kazalar için 1. ve 2. ana bileşenler için en etkili parametrelerin gün (gece), gün (gündüz), çok araçl, tek araçlı, tipi (yoldan çıkma), kavşak yok, kavşak var, yüzey (kuru), yüzey (1slak) olduğu belirlenmiştir (Şekil3). Gün (gündüz), yüzey (kuru), hava (açık), düşey (eğimsiz), yatay (aliyman), yerleşim içi, kavşak var parametreleri pozitif korelasyona sahiptir. Gün (gece), yüzey (1slak), hava (yağmurlu), düşey (eğimli), yatay (kurp), yerleşim dışı, kavşak yok parametreleri pozitif korelasyona sahiptir. Yüzey (kuru) ve hava (açık) parametrelerinin çok yüksek pozitif korelasyona sahip olması trafik kazası verilerinin anlamlı olduğunu da göstermektedir (Şekil 3). Gün (gündüz), yüzey (kuru), hava (açı), düşey (eğimsiz), yatay (aliyman), yerleşim içi, kavşak var, tek araçlı yaralanmalı trafik kazalarında kaza oluşum tipinin yoldan çıkma şeklinde olduğu söylenebilir (Tercan, 2017). 


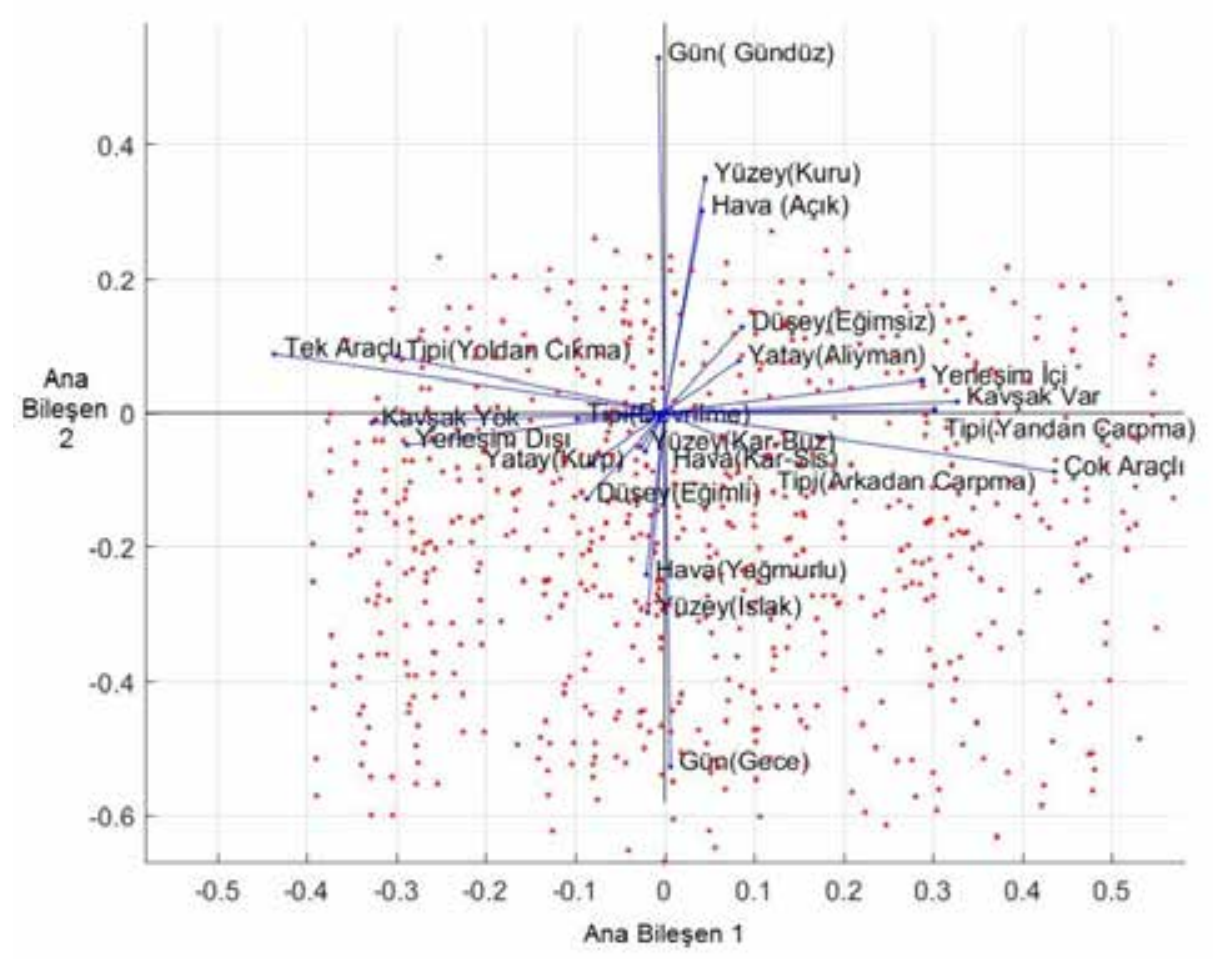

Şekil 3. Yaralanmalı trafik kazası verilerine ait biplot analizi (Tercan, 2017).

Yapılan biplot analizleri sonucunda, gün (gece), gün (gündüz), çok araçlı, tek araçlı, tipi (yoldan çıkma), kavşak yok ve kavşak var parametreleri ölümlü ve yaralanmalı kazalarda en önemli 6 parametre olarak belirlenmiştir (Tercan, 2017).

\section{SONUÇ VE ÖNERILER}

Çok değişkenli bir yapıya sahip trafik kazası verilerinin görsel şekilde açıklanması oldukça karmaşıktır. Çok değişkenli veri setinin geometrik olarak daha az boyutta yorumlanmasında biplot analizi oldukça kullanışlı bir yöntemdir.

Koruyucu, uyarıcı ve önleyici tedbirlerin alınması ve trafik yönetim planlaması için trafik kazalarına etki eden parametreler arasındaki ilişkilerin değerlendirilmesi gerekmektedir. Trafik kazaları veri setinin TBA biplot analiz yöntemi ile değerlendirilmesi sonucunda; gün (gece), gün (gündüz), çok araçlı, tek araçlı, kaza tipi (yoldan çıkma), kavşak yok ve kavşak var parametreleri ölümlü ve yaralanmalı kazalarda en önemli parametreler olarak belirlenmiştir. Yapılan bu çalışma ile trafik kazalarını azaltıcı ve önleyici tedbirlerin geliştirilmesine katkı sağlanacak ve gelecekte yapılacak çalışmalara önemli bir zemin oluşturulacaktır.
Trafik kazalarının analizinde kullanılan parametrelerin yeterliliği oldukça önemlidir. $\mathrm{Bu}$ kapsamda yol geometrisi, yol tasarımı, yol üst yapı durumu (üst yapı terleme alanı, makro ve mikro dokudaki sürtünme katsayısı, cilalanma, tekerlik izinde oturma, çatlak üst yapı alanı, ondülasyonlar ve yığglmalar gibi) gibi yoldan kaynaklı parametrelerin dikkate alınması gereklidir. Araç kaynaklı (araç lastik durumu, araç manevra kabiliyeti, fren, araç ön ve arka lambaları, hava yastığının açılıp açılmaması gibi) ve insan kaynaklı (yaş, cinsiyet, medeni durum ve gelir durumu, eğitim düzeyi, yorgunluk, uyku hali, dikkat bozukluğu, saldırganlık, duyu organlarından kaynaklı kusurlar, kas-iskelet sistemi bozuklukları ve algılama yeteneği gibi) faktörlerin ayrıca dikkate alınması gereklidir (Tercan, 2017). Bulanık parametreler olarak kaza esnasındaki araç hızı, yağmur seviyesi ve şiddeti, yol aydınlatma koşulları, görüş mesafesi ve dever miktarı, otokorkuluk dikme aralıklarının ve yüksekliklerinin durumu, kavşak tasarım hatalarından kaynaklı sorunlar, kazanın meydana geldiği andaki taşıt yoğunluğu, trafik işaretleri, emniyet kemerinin kullanım durumu gibi parametrelerin trafik kaza tespit tutanaklarında derecelendirilmiş bir şekilde işlenmesi önerilmektedir (Tercan, 2017). 
Trafik kazalarına etki eden parametreler arasındaki ilişkilerin daha iyi kavranması için önerilen tüm parametrelerin dikkate alınarak değerlendirilmesi ve trafik kaza tespit tutanaklarının bu parametrelere göre yeniden düzenlenmesi ile muhtemel trafik kazalarını ve kazalar sonucunda meydana gelebilecek ölüm, yaralanma, iş gücü kaybı ve ekonomik zararların elemine edilmesine katkı sağlanacaktır.

\section{KAYNAKLAR}

Al-Ghamdi A, 2002. Using logistic regression to estimate the influence of accident factors on accident severity. Accident Analysis and Prevention, 34 (6): 729-741.

Alikhani M, Nedaie A, Ahmadvand A, 2013. Presentation of clustering classification heuristic method for improvement accuracy in classification of severity of road accidents in Iran. Safety Science, 60: 142-150.

Alkan BB, 2011. Çok Değişkenli İstatistiksel Yöntemlerde Biplot Tekniği. Ankara Üniversitesi Fen Bilimleri Enstitüsü, Doktora Tezi, Ankara, $121 \mathrm{~s}$

Alkan BB, Atakan C, Akdi Y, 2015. Visual analysis using biplot techniques of rainfall changes over Turkey. MAPAN-Journal Of Metrology Society Of India, 30 (1): 25-30.

Alkan BB, Atakan C, 2011. Use of canonical variate analysis biplot in examination of choline content data of some foods. International Journal of Food Sciences and Nutrition, 62 (2):171-174.

Chang LY, Chien JT, 2013. Analysis of driver injury severity in truck-involved accidents using a non parametric classification tree model. Safety Science, 51: 17-22.

Çodur MY, Tortum A, Çodur M, 2013. Genelleştirilmiş lineer regresyon ile Erzurum Kuzey Çevre Yolu kaza tahmin modeli. Iğdır Üniversitesi Fen Bilimleri Enstitüsü Dergisi, 3 (1): 79-84.

De Oña J, Mujalli RO, Calvo FJ, Lopez G, 2013. Analysis of traffic accidents on rural highways using Latent Class Clustering and Bayesian Networks. Accident Analysis and Prevention, 51: 1-10.

Eckart C, Young G, 1936. The approximation of one matrix by another of lower rank, Psychometrika 1: 211-218.

Esteban VA, Villardón MPG, Sánchez IMG, 2017. Cultural values on CSR patterns and evolution: A study from the biplot representation. Ecological Indicators, 81: 18-29.

Faes AAD, Costas R, Galindo MP, Bordons M, 2015. Unravelling the performance of individual scholars: Use of Canonical Biplot analysis to explore the performance of scientists by academic rank and scientific field. Journal of Informetrics, 9 (4): 722 733.

Gabriel KR, 1971. The biplot graphic display of matrices with application to principal component analysis. Biometrika, 58 (3): 453-467.

Gabriel KR, 1978. Least squares approximation of matrices by additive and multiplicative models. Journal of the Royal Statistical Society, Series B, 40 (2): 186-196.
Trafik kazalarını azaltabilmek için sürücü, yolcu ve yaya eğitim seviyesinin geliştirilmesi ve kamu spotu yoluyla toplumun trafik konularında bilgilendirilmesi gereklidir. Trafik kaza verilerinin analizi ve ileriye yönelik gerçekçi stratejiler geliştirilmesi için ulusal yol bakım-işletme ve kaza bilgi sistemlerinin geliştirilmesi yararlı olacaktır (Tercan, 2017).

Gardner S, le Roux NJ, 2005. Extensions of biplot methodology discriminant analysis. Journal of Classification, 22: 59-86.

Gower JC, Hand DJ, 1996. Biplots. Chapman and Hall, London, 277 pp.

Gower JC, 2004. The geometry of biplot scaling. Biometrika, 91 (3): 705-714.

Gower JC, Lubbe S, le Roux NJ, 2011. Understanding Biplots. John Wiley and Sons, Chichester, United Kingdom.

Kabak D, Akçura M, 2017. Bingöl ilinden toplanan yerel çavdarlarda tane verimi ve bazı özellikler arasındaki ilişkilerin biplot analizi ile incelenmesi. Türk Tarım ve Doğa Bilimleri Dergisi, 4 (2): 227-235.

Kadariya M, Glover KD, Mergoum M, Osborne LE, 2008. Biplot analysis of agronomic and fusarium head blight resistance traits in spring wheat. Journal of Crop Improvement, 22 (2): 147-170.

Kashani AT, Mohaymany AS, 2011. Analysis of the traffic injury severity on two-lane, two-way rural roads based on classification tree models. Safety Science, 49: 1314-1320.

Kendal E, Tekdal S, Aktaş H, Karaman M, Berekatoğlu K, Doğan $\mathrm{H}, 2014$. Biplot analizi kullanılarak yazlık arpa genotiplerinin verim ve verim unsurlarının belirlenmesi. Trakya University Journal of Natural Sciences, 15 (2): 95-103.

KGM, 2016. Trafik Kazaları Özeti 2016. Karayolları Genel Müdürlügü, Ankara, Türkiye, 17s.

Kim SK, McKay D, Taylor S, Tolin D, Olatunji B, Timpano K, Abramowitz J, 2016. The structure of obsessive compulsive symptoms and beliefs: A correspondence and biplot analysis. Journal of Anxiety Disorders, 38: 79-87.

Kunt M, Aghayan I, Noii N, 2012. Prediction for traffic accident severity comparing the ANN, genetic algorithm, combined genetic algorithm and pattern search methods. Transport, 26 (4): 353-366.

Librero NAB, Sierra C, Galindo VMP, Barzola RO, Villardón GMP, 2017. Clustering Disjoint HJ-Biplot: A new tool for identifying pollution patterns in geochemical studies. Chemosphere, 176: 389-396.

Martín MIG, Palacios VV, Revilla I, Quintana AMV, Hierro JMH, 2017. Discrimination between cheeses made from cow's, ewe's and goat's milk from unsaturated fatty acids and use of the canonical biplot method. Journal of Food Composition and Analysis, 56: 34-40.

Mujalli RO, De Ona J, 2011. A method for simplifying the analysis of traffic accidents injury severity on two-lane highways using Bayesian Networks. Journal of Safety Research, 42 (5): 317326. 
Oyedele OF, Lubbe S, 2015. The construction of a partial least-squares biplot, Journal of Applied Statistics, 42 (11): 2449-2460.

Sayar MS, Han Y, 2015. Mürdümük (Lathyrus sativus L.) Hatlarınin tohum verimi ve verim komponentlerinin belirlenmesi ve GGE biplot analiz yöntemiyle değerlendirilmesi. Tarım Bilimleri Dergisi, 21: 78-92.

Sierra C, Ruíz-Barzola O, Menéndez M, Demey JR, Vicente-Villardón JL, 2017. Geochemical interactions study in surface river sediments at an artisanal mining area by means of Canonical (MANOVA)-Biplot. Journal of Geochemical Exploration, 175: 72-81.

Tekdal S, Kendal E, Ayana B, 2014. İleri kademe makarnalık buğday hatlarının verim ve bazı kalite özelliklerinin biplot analiz yöntemi ile değerlendirilmesi. Türk Tarım ve Doğa Bilimleri Dergisi, 1 (3): 322-330.

Tercan E, 2017. Karayolu Güvenliğinde Esnek Hesaplama Tekniklerinin Kullanılması. Erciyes Üniversitesi Fen Bilimleri Enstitüsü, Doktora Tezi, Kayseri, 113s.
Tortum A, Çodur MY, K1lınç B, 2012. Modeling traffic accidents in Turkey using regression analysis. Iğdır University Journal of the Institute of Science and Technology, 2 (3): 69-78.

WHO, 2016. World health statistics 2016: Monitoring Health for the SDGs. ISBN 978924156526 4, Switzerland.

Yau K, 2004. Risk factors affecting the severity of single vehicle traffic accidents in Hong Kong. Accident Analysis and Prevention, 36 (3): 333-340.

Zhang PP, Song H, Ke XW, Jin XJ, Yin LH, Liu Y, Qu Y, Su W, Feng NJ, Zheng DF, Feng BL, 2016. GGE biplot analysis of yield stability and test location representativeness in proso millet (Panicum miliaceum L.) genotypes. Journal of Integrative Agriculture, 15 (6): 1218-1227. 